\title{
"Developing a channel strategy decision support framework for a diesel engine supplier in Mozambique"
}

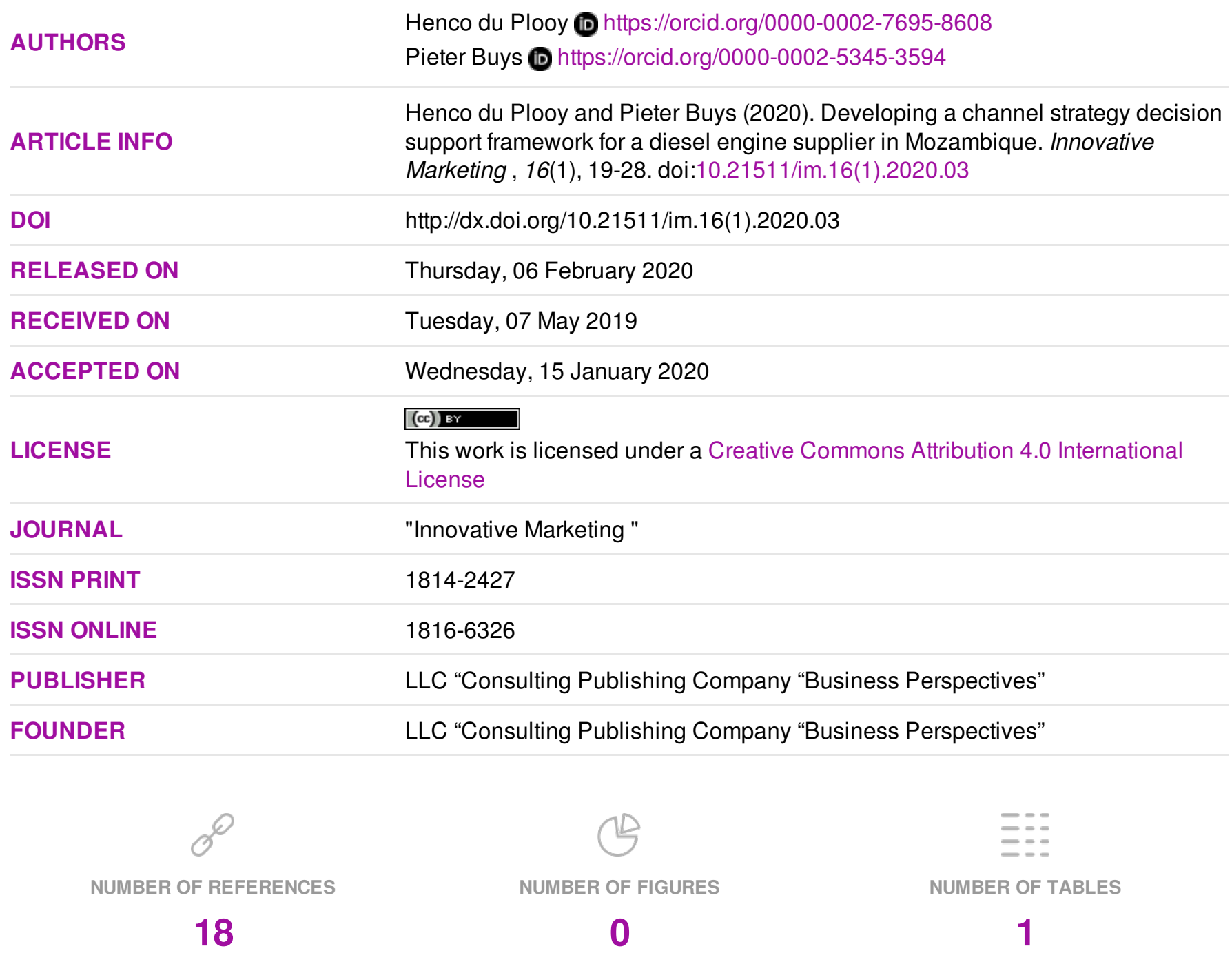

(c) The author(s) 2022. This publication is an open access article. 


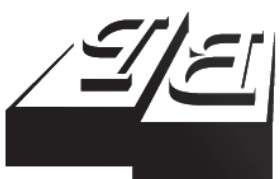

BUSINESS PERSPECTIVES

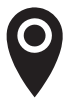

LLC "CPC "Business Perspectives" Hryhorii Skovoroda lane, 10, Sumy, 40022, Ukraine

www.businessperspectives.org

Received on: $7^{\text {th }}$ of May, 2019 Accepted on: $19^{\text {th }}$ of January, 2020

(C) Henco du Plooy, Pieter Buys, 2020

Henco du Plooy, Ph.D. Candidate, Management Cybernetics Research Unit, North-West University, Potchefstroom, South Africa.

Pieter Buys, Professor, Director, Management Cybernetics Research Unit, North-West University, Potchefstroom, South Africa.

\section{(c) (1)}

This is an Open Access article, distributed under the terms of the Creative Commons Attribution 4.0 International license, which permits unrestricted re-use, distribution, and reproduction in any medium, provided the original work is properly cited.

\section{DEVELOPING A CHANNEL STRATEGY DECISION SUPPORT FRAMEWORK FOR A DIESEL ENGINE SUPPLIER IN MOZAMBIQUE}

\begin{abstract}
The global economic competitiveness has forced many organizations to consider the emerging and developing markets for future growth opportunities. The Southern African country Mozambique was identified as such an opportunity. However, although the country has experienced more sustained historic economic growth than its neighboring countries, it is also riddled with corruption and bureaucracy. Due to the complex and challenging Mozambique business environment, this research project utilized SWOT and PESTLE analytical techniques to develop a decision support framework to support the organizational growth strategies in Mozambique. The approach allowed for both internally and externally focused data collection and evaluation. The qualitative data were collected during structured interviews with selected captains-of-industry in the Mozambican context. In the development of the decision support framework, key factors were identified, evaluated, and ranked in order of severity. Key internal factors found centered on human resources, including management style, skilled labor availability and retention, while external factors centered potential growth in the mining and gas industry, government interventions and stability, and lack of skilled labor availabity. Taking cognizance of these factors enables a systematic framework to guide the strategy development in the Mozambican marketplace. It is recommended that this framework should be a living framework, continuously evolving as new strategic information becomes available.
\end{abstract}

\section{Keywords}

JEL Classification business intelligence, emerging markets, PESTLE analysis, strategic management, SWOT analysis

\section{INTRODUCTION}

The highly competitive and dynamic global economic environment seems to be forcing more and more companies into considering the developing economies, including those in Africa, as key to their future opportunities. Due to its good global economic performance of the past decade or so, Mozambique has been identified as such an investment possibility. Earlier research in the Mozambican business environment conducted by Du Plooy (2016) found that, although the country experienced remarkable growth in a region where its neighbors sometimes battled to achieve only a third of the growth that Mozambique achieved, its rating on the global Ease of doing business (Trading economics, 2019) and Corruption (Transparency International, 2012) indices portrayed Mozambique as a very hostile environment loaded with risk for foreign organizations. Taking the above into consideration, the concern is raised about the sustainability of the growth experienced in Mozambique due to, among others, its dependence on China. 
The aforementioned notwithstanding, the holistic business climate remains very unclear. Olivenca (2013) concluded that although Mozambique holds a wealth of opportunities for foreign investors, developers, and contractors, there is undoubtedly still some residual risk involved in investing in developing economies such as Mozambique. Despite its low ranking on the Ease of doing business and the Corruption indices referred to earlier, reports and articles by Douglas (2012), KPMG (2013), Macauhub (2014), and Olivenca (2013) portray Mozambique as a resource-rich and diverse economy whose development will not only benefit own economy but also that of the landlocked countries surrounding it. Done (2012), however, cautions against 12 global trends, many of which already feature as prominent threats by the Office of the Director National Intelligence and the National Intelligence Council of the United States of America, which need to be considered as potential hurdles when considering investing in global economies. These threats include geopolitical power shifts, war, terrorism and social unrest, climate change, water and food security, education, energy, health and natural disasters, and others.

As indicated above, Du Plooy (2016) conducted an exploratory study on the Mozambican economic development potential and the sustainability of the growth it was experiencing at the time, thereby possibly providing foreign investors with a glimpse into the realities about the Mozambican business environment, the markets, as well as potential competitors and clients. That study also noted that the type of economic growth Mozambique experienced in recent times not only benefitted the country and its residents in itself, but the upgrading and expansion of roads, ports, and rail infrastructure also led to positive developments for its neighboring countries.

In light of the above, the primary research objective of this paper revolved around the development of a high-level decision support framework for potential channel development strategies in the Mozambican marketplace, and then specifically for the case study organization (Company A). In reaching a satisfactory outcome to this objective, the following three secondary objectives were identified, namely:

- analysis and interpretation of the information (about the Mozambican business environment) obtained during the initial empirical research in order to come to a fundamental understanding of the said business environment, i.e., the business problem diagnosis and formulation aspects;

- using the aforementioned acquired knowledge to develop a potential decision support framework, i.e., the artifact creation aspect;

- reflection on the resultant decision support framework, specifically to develop and embed a future growth strategy support model, i.e., the reflection and learning aspects.

In achieving the objectives, the paper included a literature study aimed at underpinning the research motivation, field of study and the fundamentals of strategy development, which is then followed by 1) the explanations of the employed research methodology and 2) the empirical research phases, i.e., the problem diagnosis, the artifact creation, and the reflection aspects. The paper is then finally rounded off with a concluding discussion.

\section{LITERATURE REVIEW}

Many reasons can be put forward as to why markets are changing, including 1) the discovery of new mineral resources, 2) infrastructure development connecting demand and supply markets, 3) evolving customer needs, 4) new market entrants, 5) technological developments, and even 6) new polices and legislation being introduced (Analoui \& Karami, 2003; Cecchetti, 2008). Furthermore, global organizations often have a limited understanding of the effect of individual country economies on their current and future business strategies (Ireland, Hoskisson, \& Hitt, 2009, pp. 35-36). It may be argued that the economic growth experienced by Mozambique is powered by diesel-pow- 
ered generators and heavy-duty machinery ( $\mathrm{Du}$ Plooy, 2016). As a global player in the manufacturing and aftermarket support of diesel-powered engines, Company A understands that it has to take advantage of this growth opportunity. It planned to accomplish this through a channel-to-market model that guarantees the availability of its products to the Mozambican market and to provide after-sales support to its products. The company employs a four-pillar operating system, focusing on 1) power generation, 2) engines, 3) distribution, and 4) components in selling its engines to original equipment manufacturers (OEMs) as firsttime fitments through a network of distributors by way of joint ventures and direct to end-user customers for re-power opportunities.

Although differentiation from its competitors has always been key, it is acknowledged that a well-established global brand does not automatically translate into being able to bring excellent service and support to customers. Because of this, the company also acknowledges that it will have to further its aftermarket sales and support capabilities in line with their customers' expanding global footprint. However, among the constraints being experienced is the uncertainty attached to the macro- and micro-business/economic environments of the countries and territories on their radar. Due to the diversity experienced in the Mozambican economy and operating surroundings, we utilized a two-pronged analysis approach, inclusive of internal and external perspectives. Firstly, we employed competitive organizational analysis, being cognizant of the internal strengths and weaknesses, as well as the external opportunities and threats (SWOT). Secondly, we deepened our research into the external environment, using a business environmental analysis, cognizant of the political, economic, sociocultural, technological, legal, and environmental aspects (PESTLE). This research project, however, not only applied these analysis techniques to understand the business environment better but it also demonstrates how these tools can play a key role in the formulation of an organization's business expansion strategy.

In terms of the SWOT analysis, Carpenter and Dunung (2011) believe that it is a strategic management tool that helps an organization in un- derstanding its internal characteristics (i.e., its strengths and weaknesses) and based on that understanding, developing the strategies that build on its strengths while minimizing risks evolving from any weaknesses it might have. This will subsequently assist in the assessment of the external environment for opportunities and threats that may potentially contribute and/or detract from the organizational strategies. Building hereon, Carpenter and Dunung (2011) also demonstrated that when an organization is considering an entry into new markets, a PESTLE analysis will provide insight into the status of key market-flatteners, both in terms of its present state and future trends. Gillespie (2014) advises that organizations need to consider which PESTLE factors are most likely to impact their business, should a change in such a factor take place, and then to proactively look for key identifiers as early warning signs. Nishada (2012) argued that due to the advantages and the disadvantages associated with both the SWOT and PESTLE analyses, it is advisable to combine the two to attain the best possible analysis before crafting the anticipated strategy, as indicated below. This approach is followed in this paper.

\section{METHODS}

The research methodology is based on the design sciences research (DSR) paradigm, and then specifically utilizing aspects of the elaborated action design research (eADR) approach per Mullarkey and Hevner (2018). This approach was developed as the response to a need for a research method that explicitly recognizes the artifacts as ensembles emerging from design, use and ongoing refinement within the organizational context (Sein, Henfridsson, Purao, Rossi, \& Lindgren, 2011), which should generate design knowledge by creating an artifact that addresses an organizational need for intervention (Mullarkey \& Hevner, 2018). This requires both the identification of the requisite underlying academic theories and the verification thereof in business reality.

The eADR process has four phases, namely 1) diagnosis, 2) design, 3) implementation, and 4) evaluation. These stages again, each consists of five activity cycles, namely problem formulation and planning, artifact creation, evaluation, reflec- 
tion, and learning (Mullarkey \& Hevner, 2018). According to Mullarkey (2018), researchers can enter the research continuum at multiple points, depending on the specific requirements of the project. As for the research objectives highlighted earlier, this paper revolves around the first diagnostic, problem-centered phase, mentioned above. In executing the research, the researcher relied on a true-to-life approach that included interviews, observations, and analysis of selected contributors to the Mozambican economy. A qualitative research approach was chosen, as such an approach fits exploratory studies best when the extent of the business problem is not known. The following are pertinent to this paper:

- the sampling design criteria used in selecting the participants were based on 1) their ex-pat status, 2) the markets they are functioning in, and 3) their reliance on a steady economic environment. All the participants were dependent on diesel-powered engines, such as those supplied by Company A. A total of ten organizations with operations across Mozambique participated, resulting in data saturation with similar trends and responses being found;

- a structured interview approach was followed to come to an understanding of participants' views and perceptions and to provide them with an opportunity to air their opinions about the developments in Mozambique. As such, it enabled follow-up questions where clarity was required. To ensure that no important information was missed, the answers were recorded;

- framework coding techniques were employed for data analysis based on analytical framework (the literature review). Additional categories did, however, emerge from the analysis of the transcripts. The data from the transcriptions were analyzed according to the categories as identified.

\section{RESULTS}

Briefly, in terms of demographics, the majority of participants were older than 40 years, and $70 \%$ of them were on ex-pat assignments. The sectors covered included engineering (35\%), construction (19\%), retail (15\%), mining (12\%), agriculture $(12 \%)$, and automotive (8\%). The most common channel-to-market $(66 \%)$ was that of organization-owned brick-and-mortar, and only about a third of participants utilized a channel combining representatives/dealers and organization-owned resources.

The following information was gained from the SWOT analysis phase of the empirical study (refer Table 1):

strengths: when asked to rank the strengths that the participants considered their organization had to have to be successful in Mozambique, most selected the leadership team as most important. The order of importance for the remainder of requirements was relevant critical skills, market share, supplier relations, organizational footprint, sales and marketing activities, and global size of the organization. A common theme throughout all the interviews was the acknowledgment of the lack of available skilled labor in Mozambique and that skilled labor not only resulted in enhanced product quality but also the revenue potential. Some participants noted that succession planning and overall organization contingency relied on the ability of the existing skilled labor to transfer skills and knowledge gained to new appointees. Although the market share and global size of the organization gave comfort to the local operations, it did not matter much to the local customers. Some of the participants cited that Mozambican suppliers are treated as valuable partners and that having good relationships with reliable suppliers is key to growth prospects. From the feedback received, it was evident that conventional marketing was very effective, primarily due to the vast areas to be covered and limited availability of advertising media;

- weaknesses: from the responses received when asked to rank the weaknesses the organization should guard against, the participants again rated the availability of skilled labor as their primary concern (or weakness). Retaining the services of ex-pats and skilled labor because of the lack of basic infrastructure resulting in 
them not being able to bring their families to join then was listed as the second biggest concern. Their ability to effectively advertise and market their products across Mozambique due to the factors mentioned above was rated the third most worrying factor, and the ability to speak the local languages was mentioned as the fourth biggest concern. Funding from abroad and supplier relations were noted as no concern due to the ease of transferring funds to Mozambique and the practice of treating suppliers as reliable partners in their organizations;

- opportunities: the literature research has presented Mozambique as a country with diverse and abundant opportunities for the right business partner. Participants voiced the same opinion, especially in light of the proven gas resources in the north-eastern part of Mozambique and the potential developments associated with it. The increasing exploration and mining activities across Mozambique was rated as the second largest opportunity. The success of these two opportunities could also be credited for the third largest, namely the government's spending on infrastructure and the growth in construction projects. Other mentionable opportunities that were mentioned were the growth in agriculture, infrastructure developments, marine and rail sector growth and developments and access to and from neighboring countries due to these rail and marine expansions;

- threats: it was no surprise that the lack of local skilled labor was ranked as the main threat to conducting successful business in Mozambique. While the average response placed political stability as the second most concerning factor, it should be said that most of the participants who registered this as their major concern had operations in the regions where RENAMO (an opposition political party) was influential. The process that must be followed and the conditions that must be adhered to before foreign employees' working permits could be renewed was ranked at number three. From the interviews, it seemed like consistency in applying the law between regions was the main issue of concern. Furthermore, as it is a trend in the Southern African region to force organizations to have a portion of local ownership in their companies, this was also a common threat mentioned by all participants. Other issues that were presented as threats included Mozambique's foreign exchange regulation, the increase of competitors due to the growing organization opportunities, the health and safety of employees due to the lack of infrastructure, and the impact of seasonal and environmental changes. Regarding the former, it was mentioned that transport and access to rail and roads during the rainy season in central Mozambique often come to a standstill for weeks at the end.

The following information was gained from the PESTLE analysis aspect of the study (refer Table 1):

- political environment: most participants believed that government policies and legislation directly impacted their organization and that this impact would be negative in the foreseeable future. In terms of the political factors that may have an impact, political activities were considered the main obstacle. In light of only $20 \%$ of the participants having had local shareholding, one can appreciate that the issue of local ownership was a concern. It was also agreed that it would be difficult to oust the ruling FRELIMO party - hence, political instability was a minor concern;

- economic environment: all the participants agreed that they do not expect the Mozambican economy to worsen from its current state. The participants were somewhat divided on what to expect from the currency and inflation performances in the next few years. They did, however, agree that unemployment would impact negatively on the economy. Even though most participants believe that unemployment levels would negatively affect the economy, no convincing evidence to that perception could be found, especially in light of the low base level from which the economy comes. It was agreed that given the low levels of crime, crime as such should not deter foreign investment; 
- socio-economic environment: most participants agreed that the government did not do enough to improve the social environment. Most participating companies had a diverse workforce, and almost all of them had community improvement plans in action and therefore believed that their organization was doing enough in this regard. This was not unexpected since the government expects community improvement actions from all foreign companies. In follow-up discussions, the participants alluded to the fact that although socio-economic development is the responsibility of the government, they are willing to work together in this arena;

- technology environment: information received from the technology questions had most of the participants indicating that they used fixed-line, mobile, 3G, and/or Wi-Fi networks as methods of communication. Although they indicated that they had sufficient access to $\mathrm{Wi}-\mathrm{Fi}$ and the internet and that fixed-line connections were stable and reliable, the mobile networks were very much unreliable with technological support practically non-existent. Participants replied in a follow-up conversation that the latter was one of the biggest technology concerns;

- legal environment: although legislation can provide powerful incentives in encouraging foreign investors, an over-regulated environment can have the opposite result. It was clear that even though companies prefer to use local legal representatives, they did not fully trust the local justice system. Expatriating funds back to holding companies was sometimes considered a difficulty. When asked to rank the most difficult legislation and laws to understand and apply, the import and export regulations, labor law and applying for or renewing work permits ranked as the most difficult;

- environmental factors: governments often place levies on polluting organizations, while rewarding those having a positive environmental effect. Participants agreed that they felt the government did not do enough to improve national healthcare, the supply of clean water, establishing reliable electricity networks with broad coverage across Mozambique, quality housing, schools, and constructing more accessible roads. The lack of available skilled labor in Mozambique was raised as a major concern by all participants. The greater part of the participants felt that seasonal climate changes, although severe at times, did not have that big influence on their organizational activity. When asked to rank environmental factors in the order that it could impact their organizational activity the most, they mentioned healthcare, lack of local skilled labor, sound transport infrastructure, and electricity networks and supply. The fact that foreign companies are required to offset every foreign worker with ten local workers further burdens its ability to do business in Mozambique. All participants acknowledged the lack of sufficient housing and schools as further reasons for not being able to attract skilled labor from other countries.

Merely having the results of a SWOT and PESTLE project available is hardly adequate for effective management. What is of paramount importance is how the results can be developed into relevant information that is of strategic use. The modern-day business environment is characterized by ever-increasing economic uncertainty that may negatively impact global populations' livelihood and living conditions. This research enabled to identify some of the industry-specific and other generic issues that a diesel engine supplier may face when considering expansion into Mozambique. The benefit only becomes tangible when analyzed holistically within context. By grouping the information and identifying the trends it becomes possible to formulate effective strategies. During the interviews, it was obvious that there is a lack of market intelligence available and that the participants were all interested in the findings of the study. In light of the intelligence gained from the participants as provided above, the envisaged decision support framework is developed to systematically guide the formulation of a growth strategy, as presented in Table 1. 
Table 1. Decision support framework for strategic investment in Mozambique

\begin{tabular}{|c|c|c|c|c|}
\hline \multicolumn{3}{|c|}{ Organizational competitive analysis } & \multicolumn{2}{|r|}{ Business environmental analysis } \\
\hline \multirow{12}{*}{ 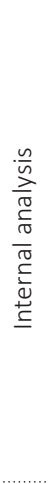 } & \multirow{6}{*}{$\mathrm{S}$} & Leadership/management style & \multirow{4}{*}{$P$} & Actions of political parties \\
\hline & & Skilled labor & & Local ownership content \\
\hline & & Market share & & Change in political leadership \\
\hline & & Customer/supplier relationships & & Political stability of neighbors \\
\hline & & Footprint in the country & \multirow{4}{*}{$E$} & Economic growth forecast \\
\hline & & Marketing and advertising & & Inflation forecast \\
\hline & \multirow{6}{*}{ W } & Availability of skilled labor & & Impact of unemployment \\
\hline & & Retention of skilled staff & & Impact of crime \\
\hline & & Language barriers & \multirow{4}{*}{$\mathrm{S}$} & Government impact on social environment \\
\hline & & Available management & & Diversity of workforce \\
\hline & & Company funding & & Company's community improvement plans \\
\hline & & Supplier relationships & & Company's impact on the social environment \\
\hline \multirow{12}{*}{ 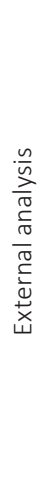 } & \multirow{6}{*}{$\mathrm{O}$} & Growth in the mining and gas industry & \multirow{4}{*}{$\mathrm{T}$} & Telecommunication usage \\
\hline & & Government spending & & Stability of fixed line and mobile networks \\
\hline & & Infrastructure development & & Internet and Wi-Fi coverage and access \\
\hline & & Foreign donor funding & & Local technology support \\
\hline & & Mergers with local entities & \multirow{4}{*}{$\mathrm{L}$} & Comprehension of local legislation \\
\hline & & Routes to neighboring countries & & Labor legislation \\
\hline & \multirow{6}{*}{$\mathrm{T}$} & Lack of suitable skilled labor & & Foreign exchange regulations \\
\hline & & Political instability in Mozambique & & Operating license requirements \\
\hline & & Work permits for foreign employees & \multirow{4}{*}{$\mathrm{E}$} & Healthcare and sanitation \\
\hline & & Local ownership in companies & & Reliable electricity coverage \\
\hline & & Health and safety of employees & & Road and transport infrastructure \\
\hline & & Foreign exchange regulation & & Housing and schooling \\
\hline
\end{tabular}

Based on the knowledge obtained from the study, it also becomes possible to develop both internally focused and externally focused intelligence in support of the above framework.

In terms of internal intelligence, firstly, it is obvious that a resilient leadership team, together with a skilled labor force, is of crucial importance for any hope of success in Mozambique. There seems to be agreement that ex-pats offer a genuine opportunity to bring the required skills into the fray, and then also to impart such knowledge into the local labor force. Nevertheless, the government's strict employment quota requirement makes it very challenging to even (temporarily) bring such skills into the country. To make matters even worse, the comparatively low educational levels in certain areas, together with language barriers, may also contribute to less than ideal knowledge transfer. However, on a positive note, the country does offer many opportunities in many sectors due the diverse nature of its economy. Growth potential for investors is, therefore, not limited to one or two industry segments.

Building on the aforementioned, in the context of external intelligence, research has indicated that the Mozambican economic environment is multifaceted and very dynamic. In general, it would seem that the challenges outweigh the benefits when considering the investment in the country. While it is clear that although Mozambique has much potential, it remains largely reliant on foreign donor investments, and much of the recent economic developments have not yet trickled down to the regular populace. While the industrial sector seems to be inclined to agree with bullish trends of economic development, expectations of the currency and inflation performances are more bearish. Crime levels seem to have little impact on organizational activities. The availability and reliability of basic infrastructures, such as clean water, schools, healthcare, stable mobile network, electricity supply and technology support, as well as road infrastructure, is very limited. On a political note, the data indicated there is a risk in the form of questionable actions from the politicians. Due to potential volatility in the political arena, the prediction of the actions and reactions of political parties is difficult. Casting a further cloud hereon is the fact that the country is also ranked as one of the more corrupt nations on the African continent. Furthermore, 
the government is somewhat under pressure to address the issue of local content in foreign organizations, which seems to be a deterrent for investment. Finally, the issue that participants considered to be the most important drawback is the lack of skilled labor. The information gathered from this study persuaded the diesel engine supplier to pursue a dealer channel to market rather than investing in a brick and mortar strategy.

\section{DISCUSSION}

From the data obtained during the interviews, it was evident that both the SWOT and PESTLE analyses may be subjective. Participants sometimes had varied responses on certain issues, perhaps due to them being from different sectors in the Mozambican economy. The user of business intelligence generated via SWOT and PESTLE analyses must always be cognizant of the fact that such generated intelligence will only be relevant if the responses and data that were received are free from undue influence, and that such intelligence should be used keeping possible bias in mind.

Like many other organizations, Company A is becoming more reliant on emerging economies for growth opportunities. According to du Plooy (2016), the drivers behind such investment imperatives are often justified by the demographic and economic statistics, such as the GDP growth trends. Khanna, Palepu, and Sinha (2005) stated that the top management teams of large corporations acknowledge that globalization is a critical challenge. One argued that this statement is still valid today. Khanna et al. (2005) were also keenly aware that it became tougher to formulate effective internationalization strategies and to identify potential countries in their internationalizing efforts. Irrespective of this, many companies seem to keep on following their 'historic' strategic approaches, often to their detriment.

Considering contemporary global economic uncertainty, it is accepted that much research and planning are essential before attempting to formulate effective organizational strategies. It is important to focus on acquiring data and intel- ligence, and not to be side-tracked by the mere profit potential. It is argued that thorough investigations into the organization and the operating conditions greatly improve the relevance and effectiveness of organizational strategies. A probable new market entrant needs to understand the significance of emerging market operation on its core operations. It also has to decide on the extent of their (long-term) commitment in trying to achieve successful market entry. Although the company considers Mozambique as having much potential, it also recognized that even if its investment in this market is strategically sound, it may still be slow to show profitable results.

To ensure that an organization considers as many variables as possible in the organizational strategy development, the results from the PESTLE analysis were considered within the context of the opportunities and threats of the SWOT analysis. Although it is relatively easy to list strengths, weaknesses, opportunities, and threats, it is often also quite easy to miss important external factors. Merely coming up with the results of each factor is not enough. In order for the SWOT to be truly successful, it is essential to carry out further analyses of all the possible threats and disadvantages to make sure that they have been planned for in advance ( $\mathrm{Du}$ Plooy, 2016). From the results of the research, it was evident that forces outside the control of the organization may have a major influence on the strategies and operations within the organization. The PESTLE analysis highlighted important factors that had to be considered during the formulation of their strategy for Mozambique. Du Plooy (2016) found that the data collected often demonstrate that organizations react differently to the external environment because of management perceptions and the quality of information. It was concluded, therefore, that organizations must plan effectively and should have comprehensive information-gathering techniques that will enable them to make better and more accurate decisions. From the responses, it was clear that managers only needed to consider which factors were most likely to change and which ones would have the greatest impact on them, i.e., each organization should identify the key factors in their environment 
and how variances in those will impact their organizational operations. For example, from the replies received during the interviews, it was clear that managers had to consider the comparative significance of multiple factors, which could be ranked or scored based on the likelihood of a change or the potential impact. The higher the likelihood of a change or the greater the impact thereof, the more crucial the specific factor is to the planning initiatives.

\section{CONCLUSION}

It was an objective of this research, in developing a decision support framework, to identify and analyze the important factors that may impact on the competitive environment of a company aiming to invest and expand into Mozambique. It was argued that if such factors are properly identified, it could assist the company in proactively planning and implementing the strategies to address these factors, and in doing so, increase the chances of success in the developing economy of Mozambique. In developing the framework per the primary objective, the identified factors are taken into consideration and are ranked in order of severity, based on the feedback from the participants. By utilizing this framework, a systematic analysis process in collecting the data and generating the intelligence is enabled. By planning accordingly, the company may also recognize the differentiating factors in Mozambique and realize potential reasons as to why a previously successful strategy used somewhere else in the world might not work in Mozambique.

In light of the above, and due to the current developments in the Mozambican economy, it is recommended that the company should not only utilize the framework but also monitor it regular by and analyze new data that may become evident. As such, the SWOT and PESTLE tools could ensure that the company keeps in touch with its competitive environment.

\section{REFERENCES}

1. Analoui, F., \& Karami, A. (2003). Strategic management in small and medium enterprises. London: Thompson. Retrieved from https://bradscholars.brad.ac.uk/ handle/10454/3231

2. Carpenter, M., \& Dunung, S. P. (2011). International business: opportunities and challenges in a flattening world, v. 1.0. Flat world education. Retrieved from https:// catalog.flatworldknowledge.com/ catalog/editions/carpenteribusinternational-business-opportunities-and-challenges-in-a-flattening-world-1-0 (accessed on March 31, 2019).

3. Cecchetti, S. G. (2008). Money, banking and financial markets (2nd ed.). New York: McGrawHill.

4. Done, A. A. (2012). The big picture: facing up to a changing world. Palgrave: MacMillan.

5. Douglas, K. (2012). Unpacking the trends shaping Mozambique's economy. Retrieved from https:// www.howwemadeitinafrica.com/ unpacking-the-trends-shapingmozambiques-economy/22084/ (accessed on March 31, 2019).

6. Du Plooy, H. (2016). Developing a channel strategy for a diesel engine supplier in Mozambique - A case study. North-West University. South Africa.

7. Gillespie, A. (2014). Foundations of economics (Additional chapter on business strategy). Oxford: Oxford University Press. Retrieved from https://global. oup.com/academic/product/ foundations-of-economics-5e$9780198739883 ? \mathrm{cc}=$ us\&lang $=\mathrm{en} \&$

8. Ireland, R. D., Hoskisson, R. E., \& Hitt, M. A. (2009). The management of strategy: concepts \& cases (8th ed.). Mason, Oh.: South Western Cengage Learning.

9. Khanna, T., Palepu, K. G., \& Sinha, J. (2005). Strategies that fit emerging markets. Harvard
Business Review, 83(6), 4-19. Retrieved from https://hbr. org/2005/06/strategies-that-fitemerging-markets

10. KPMG. (2013). Mozambique: country mining guide. Maputo: KPMG. Retrieved from https:// assets.kpmg/content/dam/kpmg/ pdf/2013/10/Mozambique-mining-country-guide.pdf (accessed on March 31, 2019).

11. Macauhub. (2014). Mozambique receives funding of US\$32 billion for infrastructure. Retrieved from http://www.macauhub.com.mo/ en/2014/07/28/mozambiquereceives-funding-of-us32-billionfor-infrastructure/ (accessed on March 31, 2019).

12. Mullarkey, M. T. (2018). SIGPRAG Workshop NWU 2018. Design Science Research (DSR). University of South Florida.

13. Mullarkey, M., \& Hevner, A. (2018). An elaborated action design research process model. 
European Journal of Information Systems, 28(1), 6-20. https:// doi.org/10.1080/096008 5X.2018.1451811

14. Nishada. (2012). SWOT Analysis vs PEST analysis and when to use them [Blog post]. Retrieved from http://creately.com/blog/diagrams/ swot-analysis-vs-pest-analysis/ (accessed on March 31, 2019).

15. Olivenca, A. (2013). Why Mozambique's future looks promising. Retrieved from https:// www.howwemadeitinafrica.com/ why-mozambiques-future-lookspromising (accessed on March 31, 2019).

16. Sein, M., Henfridsson, O., Purao S., Rossi, M., \& Lindgren, R. (2011). Action Design Research. MIS Quarterly, 35(1), 37-56. https://doi.org/10.2307/23043488

17. Trading Economics. (2019). Ease of Doing Business in Mozambique.
Retrieved from https://tradingeconomics.com/mozambique/ ease-of-doing-business (accessed on March 31, 2019).

18. Transparency International. (2012). Corruption Perception Index 2012. Retrieved from https://www.transparency.org/ cpi2012/results\#myAnchor1 (accessed on March 31, 2019). 